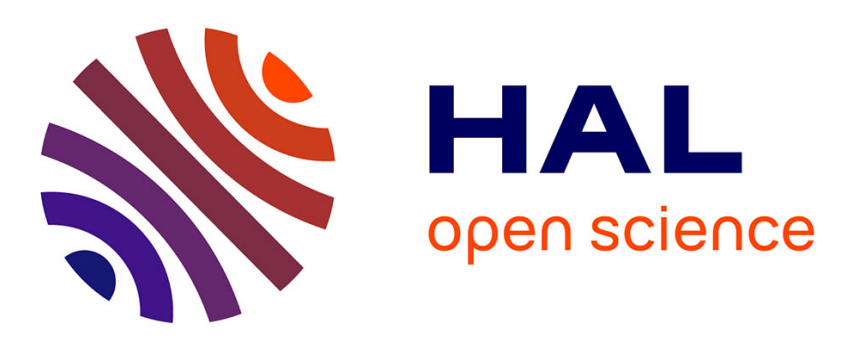

\title{
Polyhedral Oligomeric Silsesquioxane (POSS) Bearing Glyoxylic Aldehyde as Clickable Platform Towards Multivalent Conjugates
}

Nasreddine Kanfar, Ahmad Mehdi, Pascal Dumy, Sebastien Ulrich, Jean-Yves

Winum

\section{To cite this version:}

Nasreddine Kanfar, Ahmad Mehdi, Pascal Dumy, Sebastien Ulrich, Jean-Yves Winum. Polyhedral Oligomeric Silsesquioxane (POSS) Bearing Glyoxylic Aldehyde as Clickable Platform Towards Multivalent Conjugates. Chemistry - A European Journal, 2017, 23, pp.1-4. 10.1002/chem.201703794 . hal-01611638

\section{HAL Id: hal-01611638 \\ https://hal.science/hal-01611638}

Submitted on 25 May 2021

HAL is a multi-disciplinary open access archive for the deposit and dissemination of scientific research documents, whether they are published or not. The documents may come from teaching and research institutions in France or abroad, or from public or private research centers.
L'archive ouverte pluridisciplinaire HAL, est destinée au dépôt et à la diffusion de documents scientifiques de niveau recherche, publiés ou non, émanant des établissements d'enseignement et de recherche français ou étrangers, des laboratoires publics ou privés. 


\title{
Polyhedral oligomeric silsesquioxane (POSS) bearing glyoxylic aldehyde as clickable platform towards multivalent conjugates.
}

\author{
Nasreddine Kanfar, ${ }^{[a]}$ Ahmad Mehdi, ${ }^{[b]}$ Pascal Dumy, ${ }^{\left[{ }^{[a]}\right.}$ Sébastien Ulrich*[a] and Jean-Yves Winum ${ }^{*[a]}$
}

\begin{abstract}
The straightforward access to octafunctional "cubic" silsesquioxane platform grafter with pendant glyoxylic aldehydes is described. This clickable hybrid platform readily reacts with oxyamine or hydrazide compounds to provide, respectively, oxime and acylhydrazone conjugates, thereby offering a new and effective access from which one can elaborate multivalent systems for the targeting of biomolecules of interest.
\end{abstract}

Remarkable advances through the development of "chimie douce"[1] has afforded innovative organic-inorganic hybrid nanostructures. ${ }^{[2]}$ In particular, polyhedral oligomeric silsesquioxanes (POSS) are of increasing interest as a platform that can be post-synthetically functionalized in order to introduce the desired chemical moieties for the application pursued. POSS have become very popular in material sciences for various applications, for instance as porous materials, ${ }^{[3]}$ ionic liquids, ${ }^{[4]}$ catalysts, ${ }^{[5]}$ nanoreactor, ${ }^{[6]}$ nanocomposites, ${ }^{[2 a]}$ and supramolecular selfassemblies. ${ }^{[7]}$ One of the most prevalent and studied nanosized POSS is the well-defined and symmetrical $T_{8}$ structure (hexahedral octasilsesquioxane $\left.\left(\mathrm{RSiO}_{1.5}\right)_{8}\right)_{-}$ abbreviated as COSS for Cubic Octameric SilSesquioxane - which possesses a compact and rigid three-dimensional cage-like structure made of an inorganic silica-like core flanked with eight functionalizable organic groups at the corners. ${ }^{[2,8]}$ COSS are monodisperse hybrid systems of nanometric size with a precise number of functional groups which, thanks to their biocompatibility and low toxicity, ${ }^{[9]}$ are currently finding increasing applications in biological sciences, ${ }^{[10]}$ for instance in drug delivery, ${ }^{[11]}$ anti-cancer drug ${ }^{[12]}$ and biomedical imaging. ${ }^{[13]}$ This versatile class of organosilica compounds are indeed of great value as platforms for accessing multivalent conjugates for biomolecular recognition ${ }^{[14]}$ or enzyme inhibition, ${ }^{[15]}$ providing effective synthetic methods afford their complete functionalization. ${ }^{[8]}$

COSS derivatives bearing reactive functional groups such as amine, azide, vinyl, cyano, halogen have been reported

[a] N. Kanfar, Prof. Dr. P. Dumy, Dr. S. Ulrich, Prof. Dr. J.-Y. Winum Institut des Biomolécules Max Mousseron (IBMM)

UMR 5247 CNRS, ENSCM, Université de Montpellier,

8 rue de l'Ecole Normale, 34296 Montpellier Cedex (France)

E-mail: sebastien.ulrich@enscm.fr, jean-

yves.winum@umontpellier.fr

[b] Prof.Dr. Ahmad Mehdi, Institut Charles Gerhardt (ICGM) UMR 5253 CNRS, ENSCM, Université de Montpellier, Place Eugène Bataillon, 34090 Montpellier - France.

Supporting information for this article is given via a link at the end of the document in literature. ${ }^{[2,8]}$ The availability of 3-aminopropylfunctionalized $\operatorname{COSS}^{[16]}$ has prompted its functionalization through coupling with carboxylic acids, anhydrides and acyl chlorides. ${ }^{[17]}$ However, these coupling methods have a limited scope due to the lack of chemoselectivity. Therefore, click-type reactions have been recently implemented for the post-synthetic functionalization of COSS. ${ }^{[8,18]}$ The azido and vinyl derivatives have thus attracted strong interest since ligands can be effectively attached through, respectively, copper-catalyzed azide-alkyne Huisgen cycloaddition and photo-initiated thiol-ene reaction. ${ }^{[19]}$ Hydrazone and oxime ligations have also gained strong interest due to their effectiveness (quantitative yields), chemoselectivity with respect to a variety of functional groups, mild reaction conditions that do not require additional catalysts that may be toxic and difficult to discard, and lack of by-products. ${ }^{[20]}$ COSS bearing aminooxy groups have been recently reported for oxime ligation. ${ }^{[21]}$ However, having pendant amino groups can be detrimental to the stability of the COSS core, ${ }^{[22]}$ thereby reviving interest in the alternative strategy of using COSS appended with aldehyde groups. Up to now, only two examples of COSS bearing aldehyde groups has been reported..23] However, these COSS derivatives are difficult to isolate and feature aromatic aldehydes which impede water solubility and are not optimal for the stability of hydrazone and oxime conjugates. Herein, we report the effective and straightforward synthesis of a COSS bearing glyoxylic aldehydes - which are known to lead to more stable conjugates ${ }^{[24]}$ - and demonstrate the formation of multivalent conjugates through hydrazone and oxime conjugation (Figure 1).
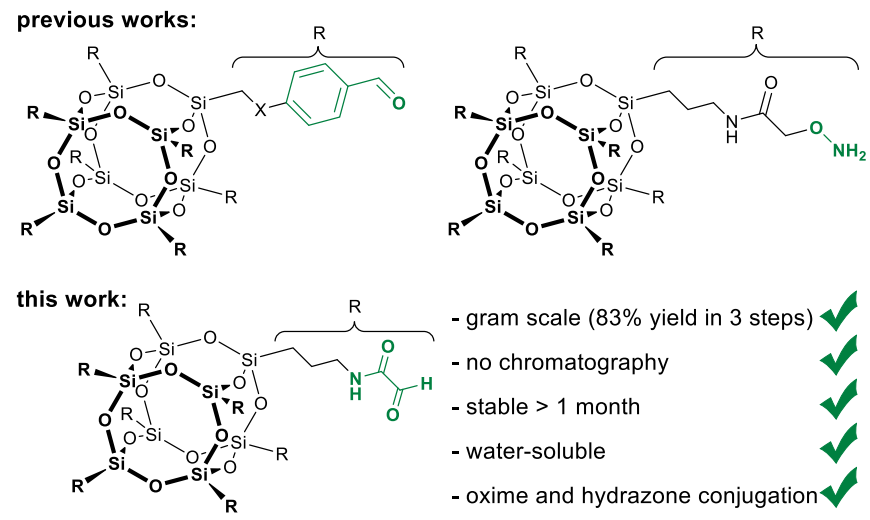

Figure 1. Summary of previously prepared COSS platform prepared for conducting oxime/hydrazone conjugates, and presentation of the platform presented here and its comparative advantages. 
The clickable $T_{8}$-silsesquioxane platform functionalized with eight glyoxylic aldehydes 4 was prepared as depicted in scheme 1, starting from the commercially available hydrochloric salt of the 3-aminopropyl substituted silsesquioxane $\mathrm{T}_{8}\left(\mathrm{CH}_{2} \mathrm{CH}_{2} \mathrm{CH}_{2} \mathrm{NH}_{3}{ }^{+} \mathrm{Cl}^{-}\right)_{8}$ 1. ${ }^{[16]}$ The peptide coupling with the protected serine Boc-L-Ser $(\mathrm{O} t-\mathrm{Bu}) \mathrm{OH}$, mediated by HBTU as coupling reagent in the presence of diisopropylethylamine (DIEA) as a base, successfully afforded compound 2 in $92 \%$ yield after recrystallization. ${ }^{1} \mathrm{H}$ and ${ }^{13} \mathrm{C}$ NMR analysis confirms the octa-functionalization of the platform (Figure S1 and S2), which is further supported by MALDI-ToF mass spectrometry (Figure S4) and elemental analysis. ${ }^{29} \mathrm{Si}$ NMR showed only one type of silicon nuclei at $-66.90 \mathrm{ppm}$ (Figure S3). This chemical shift is characteristic for $T$ substructure ${ }^{[8]}$ and expected for a $T_{8^{-}}$ POSS unit and therefore indicates that the structure of the platform remains intact. The single peak at $-66.90 \mathrm{ppm}\left(\mathrm{T}^{3}\right.$ substructure) indicates that there is no cleavage of $\mathrm{Si}-\mathrm{O}-\mathrm{Si}$ bonds (absence of signals at $-42 \mathrm{ppm}$ ( $\mathrm{T}^{1}$ substructure) and $-56 \mathrm{ppm}$ ( $\mathrm{T}^{2}$ substructure). In addition, the absence of resonance near $-100 \mathrm{ppm}$ corresponding to $\mathrm{Q}$ substructures denotes clearly that $\mathrm{Si}-\mathrm{C}$ bonds remain intact during this chemical coupling. The subsequent deprotection of Boc and $t$-Bu groups was carried out in trifluoroacetic acid (TFA)/triisopropyl silane (TIS)/water 95/2.5/2.5, giving after trituration in diethylether compound 3 in $96 \%$ yield. The complete deprotection was proved by ${ }^{1} \mathrm{H}$ and ${ }^{13} \mathrm{C} N M R$ (Figure S5, S6), MALDI-ToF mass spectrometry (Figure S8) and elemental analysis. ${ }^{29} \mathrm{Si} \mathrm{NMR}$ analysis showed a single and sharp peak at $-66,33 \mathrm{ppm}$ (Figure S7), which again confirms that no cage opening or rearrangement take place during this step. Finally, the oxidative cleavage of the amino alcohol 3 was carried out in water using a slight excess of $\mathrm{NalO}_{4}$ (8.8 eq.) Unfortunately, purification by reverse phase HPLC and size exclusion chromatography did not yield the pure compound. Dialysis was found as an easier technique to isolate the desired $\mathrm{T}_{8}$-glyoxylic aldehyde 4 which was obtained in $94 \%$ yield (see Supporting Informations). ${ }^{1} \mathrm{H}$ and ${ }^{13} \mathrm{C}$ NMR showed characteristic signals indicating that compound $\mathbf{4}$ is present exclusively in its hydrated form, respectively at $5.31 \mathrm{ppm}\left(-\mathrm{CH}(\mathrm{OH})_{2}\right)$ and $86.81 \mathrm{ppm}$ ($\mathrm{CH}(\mathrm{OH})_{2}$ ) (Figure S9-S10). ${ }^{29} \mathrm{Si} N M R$ confirmed the integrity of the $\mathrm{T}_{8}$-POSS core with a single singlet signal observed at -65.41 ppm (Figure S11). For all compounds, Thermogravimetric analysis (TGA) were conducted from 25 ${ }^{\circ} \mathrm{C}$ to $850{ }^{\circ} \mathrm{C}$ under air (Figure S21, S22, S23). The progressive weight losses assigned to the decomposition of the organic groups are around $82 \%$ for the POSS-(Boc-L$\mathrm{Ser}(\mathrm{O} t-\mathrm{Bu}))_{8} 2,80 \%$ for the POSS-(L-Ser.TFA $)_{8} 3$ and $75 \%$ for the POSS- $\left(\mathrm{C}(\mathrm{OH})_{2}\right)_{8} 4$. These values are very close to the theoretical values of, respectively, $83 \%, 81 \%$ and $76 \%$, which correspond to the loss of the organic side-chains. The difference of curve profile for compound $\mathbf{4}$ versus compounds 2 and 3 can be explained by the initial progressive dehydration of its hydrated form. IR analysis also showed characteristic absorption band of silsesquioxane cages, in particular the narrow and intense Si-O-Si vibrations which appear at 1111, 1103 and 1088 $\mathrm{cm}^{-1}$, and the Si-C vibrations which appear at 777,721 and $748 \mathrm{~cm}^{-1}$, respectively for 2,3 , and 4 (Figure S24, S25, S26).
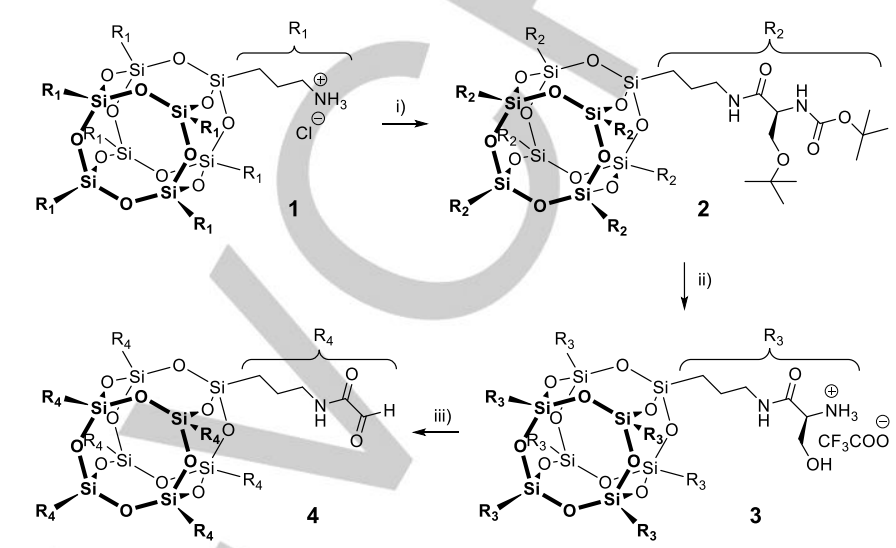

Scheme 1. Synthesis of COSS bearing glyoxylic aldehyde 4. i) Boc-L-Ser(Ot$\mathrm{Bu}) \mathrm{OH}, \mathrm{HBTU}$, DIEA, 92\%; ii) TFA/TIS/H2O 95/2.5/2.5, 96\%; iii) $\mathrm{NaIO}_{4}, 94 \%$.

Taken together, these results prove the structural integrity of the POSS platform throughout the synthesis, and show that this POSS platform $\mathbf{4}$ can be obtained in three straightforward synthetic steps, only involving recrystallization and dialysis and no column or HPLC chromatography, in an overall yield of $83 \%$ and up to the gram scale. It is also noteworthy to mention that we found compound $\mathbf{4}$ to be stable, as a solid and even in aqueous solution, for at least a month.

In order to demonstrate the utility of this platform for accessing multivalent conjugates, we carried out oxime and acylhydrazone ligation reactions (Scheme 2). The oxime ligation was carried out in acidic water $\left(\mathrm{H}_{2} \mathrm{O} / \mathrm{TFA} 99.9 / 0.1\right)$ using methoxyamine (16 eq.) as reactive partner. The acylhydrazone ligation was conducted in acidic buffer (100 $\mathrm{mM}$ sodium acetate, $\mathrm{pH}$ 5.0) as previously described, ${ }^{[25]}$ using a specific hydrazide (16 eq.) flanked with an aromatic sulphonamide that we recently prepared as carbonic anhydrase inhibitor. ${ }^{[15 a]}$ MALDI-ToF mass spectrometry show, in both cases, the complete conjugation of the eight sites (Figures S16 and S20). ${ }^{1} \mathrm{H}$ NMR data show integrals ratio converging toward complete functionalization although slight differences with theoretical values probably indicate that there are still some intermediates as minor products (Figures S13-S17). Satisfyingly, ${ }^{29} \mathrm{Si}$ NMR confirmed the integrity of the $T_{8}$-POSS core with single singlets observed at $-66.28 \mathrm{ppm}$ for compounds 5 and 6 (Figures S15 and S19). Both multivalent conjugates 5 and $\mathbf{6}$ could be successfully isolated by precipitation in, respectively, $56 \%$ and $14 \%$. Taking into account that eight ligation reactions 
take place, this amounts to individual yields of, respectively, $93 \%$ and $78 \%$.

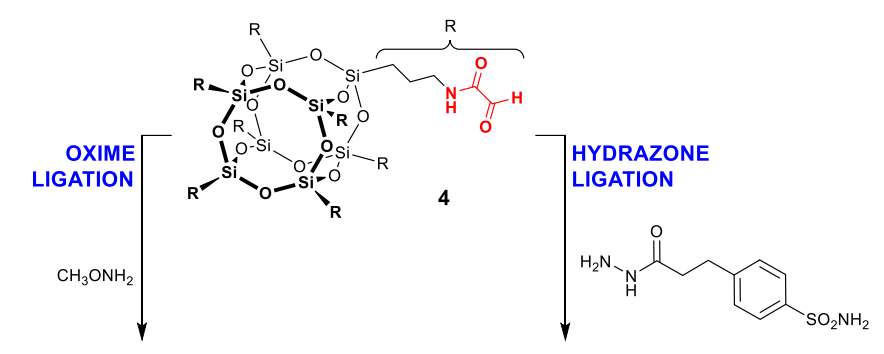

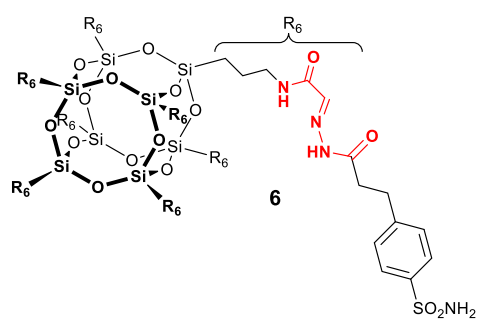

Scheme 2. Preparation of multivalent conjugates through oxime and acylhydrazone ligation reactions onto the clickable platform 4. Conditions for oxime ligation: $\mathrm{H}_{2} \mathrm{O}$ with $0.1 \%$ TFA, for acylhydrazone ligation: acetate buffer (100 mM, pH 5.0).

In conclusion, we reported here the straightforward synthesis in three steps with simple purification that enables the effective preparation, with an overall yield of $83 \%$, of a functionalized $\mathrm{T}_{8}$-POSS bearing eight reactive glyoxylic aldehyde groups. We demonstrated the structural integrity of the cOSS platform throughout the synthesis. All the cOSS-based nanostructures were extensively and unambiguously characterized via multinuclear magnetic resonance $\left({ }^{1} \mathrm{H},{ }^{13} \mathrm{C}\right.$ and $\left.{ }^{29} \mathrm{Si} \mathrm{NMR}\right)$, as well as mass spectrometry. Finally, we have shown, as proof-of-principle, that oxime and acylhydrazone ligations reactions can be effectively conducted in order to generate multivalent bioconjugates. The ease of synthesis of this novel clickable platform, coupled with the wide variety and availability of functionalized aminooxy and hydrazide derivatives provide an easy entry to elaborate multivalent systems based on a biocompatible coss core.

\section{Acknowledgements}

We acknowledge La Ligue contre le Cancer (comité des Pyrénées-Orientales) and the LabEx CheMISyst (ANR-10LABX-05-01) for funding. N.K. thanks the French Ministère de la Recherche for a doctoral fellowship.

Keywords: silsesquioxane $\cdot$ multivalent platform • oxyamine • hydrazone $\cdot$ ligations

[1] J. Livage, New J. Chem., 2001, 25, 1-1.

[2] a) Q. Ye, H. Zhou and J. W. Xu, Chem. Asian J., 2016, 11, 1322-1337; b) D. B. Cordes, P. D. Lickiss and F. Rataboul, Chem. Rev., 2010, 110, 2081-2173.

[3] P. Sangtrirutnugul, T. Chaiprasert, W. Hunsiri, T. Jitjaroendee, P. Songkhum, K. Laohhasurayotin, T. Osotchan and V. Ervithayasuporn, ACS Appl. Mater. Interf., 2017, 9, 12812-12822.

[4] a) T. Ishii, T. Enoki, T. Mizumo, J. Ohshita and Y. Kaneko, RSC Adv., 2015, 5, 15226-15232; b) K. Tanaka, F. Ishiguro and Y. Chujo, J. Am Chem. Soc., 2010, 132, 17649-17651.

[5] G. J. Chen, Y. Zhou, X. C. Wang, J. Li, S. Xue, Y. Q. Liu, Q. Wang and J. Wang, Sci Rep-Uk, 2015, 5, 11236

[6] M. Bahrami, X. Zhang, M. Ehsani, Y. Jahani and R. M. Laine, Dalton Trans., 2017, 46, 8797-8808.

[7] a) D. Voisin, D. Flot, A. Van der Lee, O. J. Dautel and J. J. E. Moreau, CrystEngComm, 2017, 19, 492-502; b) A. Boullanger, G. Gracy, N. Bibent, S. Devautour-Vinot, S. Clement and A. Mehdi, Eur. J. Inorg. Chem., 2012 , 143-150.

[8] S. Fabritz, S. Horner, O. Avrutina and H. Kolmar, Org. Biomol. Chem. 2013, 11, 2224-2236.

[9] W. H. Siddiqui and R. G. York, Fundam. Appl. Toxicol., 1993, 21, 66-70.

[10] a) H. Ghanbari, S.M. Marashi, Y. Rafiei, K. Chaloupka, A.M. Seifalian in Applications of Polyhedral Oligomeric Silsesquioxanes (Ed.: C. HartmannThompson), Springer Dordrecht Heidelberg, London, New York, 2011, pp. 363-399; b) H. Ghanbari, B.G. Cousins, A.M. Seifalian A, Macromol. Rapid Commun., 2011, 32, 1032-1046.

[11] a) S. Horner, S. Knauer, C. Uth, M. Jost, V. Schmidts, H. Frauendorf, C M. Thiele, O. Avrutina and H. Kolmar, Angew. Chem. Int. Ed., 2016, 55, 14842-14846; b) C. McCusker, J. B. Carroll and V. M. Rotello, Chem. Commun., 2005, 996-998.

[12] X. Zhang, Z. Zhang, X. Xu, Y. Li, Y. Li, Y. Jian and Z. Gu, Angew. Chem. Int. Ed., 2015, 54, 4289-4294.

[13] a) H. Strauch, J. Engelmann, K. Scheffler and H. A. Mayer, Dalton Trans., 2016, 45, 15104-15113; b) J. Henig, E. Toth, J. Engelmann, S. Gottschalk and H. A. Mayer, Inorg. Chem., 2010, 49, 6124-6138.

[14] a) E. Mahon and M. Barboiu, Org. Biomol. Chem., 2015, 13, 10590 10599; b) C. Fasting, C. A. Schalley, M. Weber, O. Seitz, S. Hecht, B. Koksch, J. Dernedde, C. Graf, E. W. Knapp and R. Haag, Angew. Chem. Int. Ed., 2012, 51, 10472-10498; c) M. Mammen, S. K. Choi and G. M. Whitesides, Angew. Chem. Int. Ed., 1998, 37, 2755-2794.

[15] a) N. Kanfar, M. Tanc, P. Dumy, C. T. Supuran, S. Ulrich and J. Y. Winum, Chem. Eur. J., 2017, 23, 6788-6794; b) N. Kanfar, E. Bartolami, R. Zelli, A. Marra, J.-Y. Winum, S. Ulrich and P. Dumy, Org. Biomol. Chem., 2015, 13, 9894-9906; c) N. Touisni, N. Kanfar, S. Ulrich, P. Dumy, C. T. Supuran, A. Mehdi and J.-Y. Winum, Chem. Eur. J., 2015, 21, 10306-10309.

[16] Z. P. Zhang, G. Z. Liang and T. L. Lu, J. Appl. Polym. Sci., 2007, 103, 2608-2614.

[17] M. Janeta, L. John, J. Ejfler and S. Szafert, Chem. Eur. J., 2014, 20, 15966-15974.

[18] S. Fabritz, D. Heyl, V. Bagutski, M. Empting, E. Rikowski, H. Frauendorf, I. Balog, W. D. Fessner, J. J. Schneider, O. Avrutina and H. Kolmar, Org. Biomol. Chem., 2010, 8, 2212-2218.

[19] a) M. L. Conte, S. Staderini, A. Chambery, N. Berthet, P. Dumy, O Renaudet, A. Marra and A. Dondoni, Org. Biomol. Chem., 2012, 10, 3269 3277 ; b) B. Trastoy, D. A. Bonsor, M. E. Perez-Ojeda, M. L. Jimeno, A. Mendez-Ardoy, J. M. G. Fernandez, E. J. Sundberg and J. L. Chiara, Adv. Funct. Mat., 2012, 22, 3191-3201; c) Y. C. Lin and S. W. Kuo, Polym. Chem., 2012, 3, 162-171; d) D. Heyl, E. Rikowski, R. C. Hoffmann, J. J. Schneider and W. D. Fessner, Chem. Eur. J., 2010, 16, 5544-5548; e) B. Trastoy, M. E. Perez-Ojeda, R. Sastre and J. L. Chiara, Chem. Eur. J., 2010, 16, 3833-3841.

[20] a) D. K. Kölmel and E. T. Kool, Chem. Rev., 2017, 117, 10358-10376; b) S. Ulrich, D. Boturyn, A. Marra, O. Renaudet and P. Dumy, Chem. Eur. J., 2014, 20, 34-41.

[21] S. Fabritz, S. Horner, D. Konning, M. Empting, M. Reinwarth, C. Dietz, B. Glotzbach, H. Frauendorf, H. Kolmar and O. Avrutina, Org. Biomol. Chem., 2012, 10, 6287-6293.

[22] F. J. Feher, K. D. Wyndham, D. Soulivong and F. Nguyen, J. Chem. Soc. Dalton Trans., 1999, 1491-1497.

[23] a) S. Chimjarn, R. Kunthom, P. Chancharone, R. Sodkhomkhum, P. Sangtrirutnugul and V. Ervithayasuporn, Dalton Trans., 2015, 44, 916- 
919; b) B. W. Manson, J. J. Morrison, P. I. Coupar, P. A. Jaffres and R. E. Morris, J. Chem. Soc., Dalton Trans., 2001, 1123-1127.

[24] O. El-Mahdi and O. Melnyk, Bioconjugate Chem., 2013, 24, 735-765.

[25] a) E. Bartolami, Y. Bessin, N. Bettache, M. Gary-Bobo, M. Garcia, P. Dumy and S. Ulrich, Org. Biomol. Chem., 2015, 13, 9427-9438; b) E.
Bartolami, Y. Bessin, V. Gervais, P. Dumy and S. Ulrich, Angew. Chem. Int. Ed., 2015, 54, 10183-10187. 
Entry for the Table of Contents (Please choose one layout)

Layout 2:

\section{COMMUNICATION}

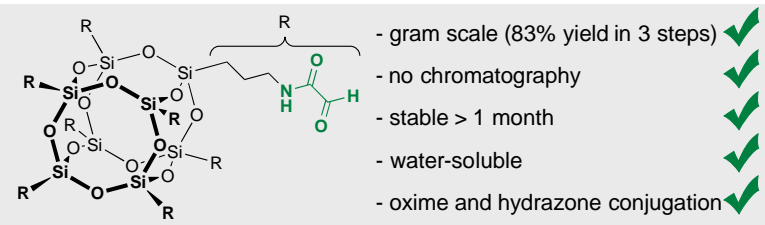

Clickable "cubic" silsesquioxane platform with glyoxylic aldehydes offers effective access to new multivalent systems via chemoselective oxime or hydrazone conjugation.
Nasreddine Kanfar, Ahmad Mehdi, Pascal Dumy, Sébastien Ulrich* and Jean-Yves Winum*

\section{Page No. - Page No.}

Polyhedral oligomeric silsesquioxane (POSS) bearing glyoxylic aldehyde as clickable platform towards multivalent conjugates. 